\title{
Climate change effects on human health: projections of temperature-related mortality for the UK during the 2020s, 2050s and 2080s
}

\author{
Shakoor Hajat, ${ }^{1}$ Sotiris Vardoulakis, ${ }^{2}$ Clare Heaviside, ${ }^{2}$ Bernd Eggen ${ }^{2}$
}

1 Department of Social and Environmental Health Research, London School of Hygiene \& Tropical Medicine, London, UK ${ }^{2}$ Centre for Radiation, Chemical and Environmental Hazards, Public Health England, Didcot, UK

\section{Correspondence to} Dr S Hajat, Department of Social and Environmental Health Research, London School of Hygiene \& Tropical Medicine, 15-17 Tavistock Place, London WC1H 9SH, UK; shakoor.hajat@|shtm.ac.uk

Received 31 January 2013 Revised 16 May 2013 Accepted 31 July 2013
To cite: Hajat $S$, Vardoulakis S, Heaviside C, et al. J Epidemiol

Community Health Published Online First: [please include Day Month Year]

doi:10.1136/jech-2013202449

\begin{abstract}
Background The most direct way in which climate change is expected to affect public health relates to changes in mortality rates associated with exposure to ambient temperature. Many countries worldwide experience annual heat-related and cold-related deaths associated with current weather patterns. Future changes in climate may alter such risks. Estimates of the likely future health impacts of such changes are needed to inform public health policy on climate change in the UK and elsewhere.
\end{abstract}

Methods Time-series regression analysis was used to characterise current temperature-mortality relationships by region and age group. These were then applied to the local climate and population projections to estimate temperature-related deaths for the UK by the 2020s, 2050 s and 2080s. Greater variability in future temperatures as well as changes in mean levels was modelled.

Results A significantly raised risk of heat-related and cold-related mortality was observed in all regions. The elderly were most at risk. In the absence of any adaptation of the population, heat-related deaths would be expected to rise by around $257 \%$ by the 2050 s from a current annual baseline of around 2000 deaths, and cold-related mortality would decline by $2 \%$ from a baseline of around 41000 deaths. The cold burden remained higher than the heat burden in all periods. The increased number of future temperature-related deaths was partly driven by projected population growth and ageing.

Conclusions Health protection from hot weather will become increasingly necessary, and measures to reduce cold impacts will also remain important in the UK. The demographic changes expected this century mean that the health protection of the elderly will be vital.

The most direct way in which climate change is expected to affect public health relates to changes in mortality rates associated with exposure to ambient temperature. Epidemiological studies show that many countries worldwide already experience appreciable annual burdens of heat-related and cold-related deaths from current weather patterns. ${ }^{1}$ In general, the risk of heat-related death in a population increases progressively once temperatures rise above specific threshold levels, and similarly the risk of cold-related death increases once temperatures drop below cold thresholds. Both the heat/cold thresholds and the strength of the relationships vary considerably between countries due to differing climatic, demographic and socioeconomic profiles. In high-income settings, few of these deaths arise due to hypothermia or hyperthermia, with the majority occurring from cardiovascular and respiratory causes. ${ }^{2}$

In the UK, thousands of preventable deaths occur annually from cold weather, ${ }^{3}$ and a smaller burden is also associated with hot weather, especially during extreme events such as the 2003 heatwave when approximately 2000 excess deaths occurred in England and Wales. ${ }^{4}$

Future changes in the climate system will quite likely alter such risks, both as a result of changes in mean temperature as well as increased variability. ${ }^{56}$ Consequently in the UK, the numbers of heat-related deaths are expected to increase in future due to warmer summers, and cold-related deaths may decrease due to milder winters, although the details remain unclear. Furthermore, owing to the concentration of risk among elderly people, both heat-related and cold-related health burdens in future may be amplified by population ageing.

Estimates of the likely future health impacts of such changes are needed to inform public health policy on climate change in the UK and elsewhere. This paper, based on a recent UK assessment of how climate change impacts on health via multiple pathways, ${ }^{7}$ details the most direct effects of temperature exposure. It models mortality relationships with current patterns of weather variability by region and age group, and applies this information to climate and population projections to estimate temperature-related health burdens for the UK during the 2020s, 2050s and 2080s.

\section{METHODS}

Estimation of future deaths associated with climate change consisted of two stages: (1) epidemiological analysis of historic weather and mortality data to characterise associations with current climate patterns; (2) risk assessment, whereby the temperature-mortality relationships from stage (1) were applied to projections of future climate, taking into account future population trends.

\section{Epidemiological analysis}

Historic mortality data

All deaths in England and Wales during 1993-2006 were obtained from the Office for National Statistics (http://www.ons.gov.uk) and aggregated to create a time-series of the daily number of deaths. As weather can contribute to mortality from many causes, series for all-cause mortality (including external causes) were created. This was carried out by age group $(0-4,5-64,65-74,75-84,85+$ years $)$ and by the 
10 government regions of England and Wales. Mortality data for Scotland and Northern Ireland are obtained from different sources and were not available for stage (1).

\section{Historic weather data}

Outdoor measurements of temperature and relative humidity were obtained from the British Atmospheric Data Centre (BADC; http://badc.nerc.ac.uk) using the UK Meteorological Office MIDAS Land Surface Stations data. Daily mean temperature and relative humidity series representative of each region were created. Only stations reporting on at least $75 \%$ of days during 1993-2006 were used, resulting in an average of 29 stations per region (minimum 7 , maximum 44). Within regions, temperature series were highly correlated (mean $r=0.96$, range $0.95-0.99$ ) and station means varied little (mean $\mathrm{SD}=0.9^{\circ} \mathrm{C}$, range $0.4-1.01$ ). Details of the averaging process and handling of missing data are published elsewhere. ${ }^{8}$ The study period included the hot summers of 1995, 2003 and 2006.

\section{Statistical model}

Time-series regression analysis was used to assess acute relationships between temperature fluctuations and daily deaths, assuming Poisson variation with scale overdispersion. Heat effects were assessed using models restricted to the summer months (June-September). Slow-changing seasonal patterns in the mortality series (unrelated to temperature) were controlled for using natural cubic splines (NCS) of time with 4 degrees of freedom per summer. Trends in mortality were modelled using linear and quadratic terms for time. NCS were also used to adjust for relative humidity, and indicator terms were used to model day-of-week effects.

For cold assessment, all-year models were adopted as cold effects may not be restricted to the winter season. Confounder control was the same as the heat models, but with additional seasonal control and inclusion of daily counts of influenza deaths.

Adjustment for air pollution exposure was not possible due to large variations in concentrations within a region. However, sensitivity analysis was conducted in the London region, where it was possible to have a representative series for particulate matter of aerodynamic diameter $<10 \mu \mathrm{m}\left(\mathrm{PM}_{10}\right)$ and ozone $\left(\mathrm{O}_{3}\right)$. Daily concentrations of both pollutants, based on current and previous day levels (lag 0-1 days), were therefore considered here.

\section{Characterisation of temperature effects}

Adjusted relationships with temperature were then assessed, first graphically using NCS of temperature to allow for assessment of the functional form of the relationship. This indicated a welldefined value of temperature (the heat threshold) above which risk of death increased in a linear fashion with high temperature, but with no increased risk in death below the threshold. Therefore, to quantify heat effects, a linear-threshold model was assumed. Heat effects occur mostly immediately, ${ }^{2}$ and so were modelled using same day and previous day temperatures. In previous work from England and Wales, the heat threshold was identified by statistical model fit as occurring at the 93rd centile of the all-year maximum temperature distribution within each region. ${ }^{8}$ As our analysis also assesses cold effects, we use mean temperature rather than maximum temperature, but assume the heat threshold at the same centile. For illustration, the 93rd centile for London corresponds to a daily mean temperature of $19.6^{\circ} \mathrm{C}$, while for the North East region it is $16.6^{\circ} \mathrm{C}$.

A cold threshold is not as well defined, indicating that an increased risk of cold-related death can occur throughout much of the year. To reflect this, a cold threshold was assumed at the 60 th centile of the all-year temperature distribution. This threshold broadly corresponds to the highest temperature value in the four coldest months of the year (December-March), excluding outliers. The 60 th centile for London is $13.2^{\circ} \mathrm{C}$, and for the North East it is $10.9^{\circ} \mathrm{C}$. As cold impacts can be delayed, they were modelled using temperatures lagged by up to 28 days. ${ }^{9}$

In addition, in the summer months a separate indicator term to represent periods of exceptionally hot weather (heat-waves) was simultaneously modelled with the general heat effect to quantify any additional mortality risk due to the more extreme temperatures occurring during a heat-wave and also due to any cumulative effects of exposure over successive hot days. This is potentially important as more frequent, more intense and longer lasting heat-waves are expected to occur in future. ${ }^{10}{ }^{11}$ Assessing the impacts of such events is often based on identifying periods of high heat intensity and duration. ${ }^{12}$ Therefore, a heat-wave was defined as a period when the mean temperature on the current day and at least the previous 2 days was above the 98th centile of the all-year temperature distribution. In contrast, there is little evidence that cold spells defined in a similar fashion have additional impacts. ${ }^{13}$

In all models, general heat (or cold) effects are presented as the relative risk (RR) of death for every $1^{\circ} \mathrm{C}$ increase (decrease) in temperature above (below) the heat (cold) threshold. RR values greater than 1 represent an increased risk in mortality compared with the annual average. RRs are estimated separately by region, as well as a mean national RR from a meta-analysis, assuming a DerSimonian-Laird random effects model.

\section{Risk assessment}

Projections of climate data

Projected daily mean temperatures for the periods 2000-2009, 2020-2029, 2050-2059 and 2080-2089 were obtained from BADC. This contains output from an ensemble of 10 available variants of the Met Office Hadley Centre Regional Climate Model (HadRM3-PPE-UK) designed to simulate regional climate in the UK for historical emissions and for the medium emissions scenario (SRES A1B) for the period from 1950 to 2100. This was then used to dynamically downscale global climate model results to a horizontal resolution of $25 \mathrm{~km}$ for use in the UKCP09 climate projections as part of the UK Climate Impacts programme. ${ }^{14} \mathrm{~A}$ subset of nine regional climate model variants corresponding to climate sensitivity in the range of $2.6-4.9^{\circ} \mathrm{C}$ was used. Temperature was calculated separately for each variant by taking the mean of the daily temperature for each grid square which fell within a particular regional boundary. This produced nine daily temperature time-series per region.

\section{Projections of population data}

Population data were extracted from the 2010-based principal projections for the UK. ${ }^{15}$ They consist of annual projections from 2010 to 2036, and then to 2081 in five-yearly increments. Projections were aggregated by age group and for four decades (2000s, 2020s, 2050s and 2080s). If the relevant year was not available, population estimates were obtained through quadratic interpolation. Although the total projections for most regions are relatively smooth and show growth until the end of this century (total UK population is projected to increase from 60 million in mid-2000s to 89 million by mid-2080s), individual age groups can show non-linearity. Future mortality trends among the oldest age groups are estimated by calculating 
mortality improvements (by age and gender) in recent years and then extrapolated for the very oldest age groups due to sparseness of data and edge effects; in future, mortality rates among the oldest age groups will continue to fall. The expansion of the $85+$ age group from around $2 \%$ of the total population in mid-2000s to $9 \%$ by the mid-2080s demonstrates the ageing of the UK population expected this century.

\section{Estimation of future mortality burdens due to climate change}

Temperature-related mortality (M) was calculated for the last decade 2000-2009 (2000s) and future decades 2020s, 2050s and 2080s using regional daily mean temperatures above/below the regional thresholds $(\Delta \mathrm{T}), \mathrm{RR}$, regional population data $(\mathrm{P})$ and baseline all-cause mortality rates (BM). The following was assumed:

$$
\mathrm{M}=\mathrm{P} \times \mathrm{BM}(\mathrm{RR}-1)
$$

$\mathrm{BM}$ is calculated from daily mortality DM excluding deaths attributable to temperature (2). DM was based on mortality rates corresponding to the 2002 estimates. The slope b is the exposure-risk relationship quantified in stage (1) (3).

$$
\begin{gathered}
\mathrm{BM}=\frac{\mathrm{DM}}{\mathrm{RR}} \\
\mathrm{RR}=\exp (\mathrm{b} \Delta \mathrm{T})
\end{gathered}
$$

The additional heat-wave component was calculated with the same method using the regional definitions and RRs. As exposure-risk relationships for Scotland and Northern Ireland were unavailable, regression coefficients from the adjacent regions of North East and North West, respectively, were used.

The temperature-mortality risk function and baseline mortality rates were held constant over the decades considered. However, the baseline mortality rates are likely to change in future as a result of socioeconomic and other changes. The risk function may also change in future as the population may partially acclimatise and adapt to higher temperatures. ${ }^{16} 17$ Our interest was in estimating the contribution of climate change on future mortality burdens, that is, in the absence of other changes, and so these possible future changes are not considered further here.

The projected annual temperature-related mortality was calculated using each of the nine regional climate model variants and then aggregated by region. The spread of the model results reflects the uncertainty in climate model physics, which is thought to be larger than the uncertainty associated with different emission scenarios. Finally, the mean, minimum and maximum mortality estimates from the nine model realisations were extracted for each region and for the UK as a whole.

\section{RESULTS}

\section{Epidemiological analysis}

Figure 1 shows the RR in all-cause mortality per $1^{\circ} \mathrm{C}$ change in current daily mean temperature. In every region, there was a raised risk in mortality associated with heat and cold exposure $(\mathrm{RR}>1)$, which was statistically significant. At the national level, there was a $2.1 \%$ (95\% CI 1.5 to 2.7 ) increase in mortality for every $1^{\circ} \mathrm{C}$ rise in temperature above the heat threshold and a $2 \%\left(95 \%\right.$ CI 1.8 to 2.2 ) increase in mortality per $1^{\circ} \mathrm{C}$ drop in temperature below the cold threshold. Although heat and cold risks were similar, there were many more days below the cold threshold than above the heat threshold, leading to a larger number of deaths attributable to cold weather.

London and East Midlands were the regions most vulnerable to heat, and the greatest cold risk was in London, the South West and Wales. In London, control for $\mathrm{PM}_{10}$ and $\mathrm{O}_{3}$ changed the heat RR from 1.039 (95\% CI 1.033 to 1.044) to 1.034 (1.028 to 1.040$)$ and the cold results were left unchanged.

Results by age group (not displayed) showed significantly raised heat and cold risks in all groups, except that there was no heat effect apparent among 0-4 year olds. In general, heat and cold risks increased with successive age groups, with the greatest risks by far occurring in those $85+$ years. Owing to imprecise estimates among the $0-4$ year group, this group was combined with the 5-64 year group for the subsequent risk assessment.

\section{Risk assessment}

Figure 2 shows the number of days in the UK in the 2020s, 2050s and 2080s that are projected to be above and below the current heat and cold threshold values, expressed as the percentage change in hot and cold days compared with the baseline period (2000s). The frequency of hot days is projected to rise steeply, with over a threefold increase by the 2080s. The number of cold days will decline at a less dramatic pace.

The estimated temperature-related deaths per year in the UK (taking the actual or projected population levels into account) during the 2000s, 2020s, 2050s and 2080s are shown in figure 3. Although the decade 2000s spans a similar time period to the historic data used in the epidemiological assessment (1993-2006), the estimates here are based on the projected climate data to allow comparison with the future decades. The mean estimate of heat-related mortality increases by approximately 66\%, 257\% and $535 \%$ in the 2020s, 2050s and 2080s, respectively, from a current baseline of around 2000 deaths. The mean estimate of cold-related mortality will increase by approximately $3 \%$ in the 2020 s, and then decreases by $2 \%$ in the 2050 s and by $12 \%$ in the 2080s, from a baseline of around 41000 deaths. The cold burden remains considerably higher than the heat burden in all periods. These predicted changes also reflect the increasing size of the population expected in most regions in this century. The population is projected to increase at a higher rate in the first three decades of this century compared with later decades. ${ }^{15}$ This increase and the ageing effect offset the expected reduction in cold-related mortality associated with climate change in the 2020s. Had the size of the population been held constant, the nationwide heat-related mortality burden would increase by $46 \%, 169 \%$ and $329 \%$ in the 2020s, 2050s and 2080s, respectively, while cold-related mortality would decrease by $9 \%, 26 \%$ and $40 \%$ over the same decades. In absolute terms, this would mean a larger reduction in cold-related deaths compared with the increase in heat-related deaths (for constant population size and age structure).

The above results do not include the additional heat-wave effect, which was only significant in the London region. This effect represented a substantial additional burden of 58\%, 64\%, $70 \%$ and $78 \%$ on heat-related mortality in London during the 2000s, 2020s, 2050s and 2080s, respectively.

Annual temperature-related deaths by age group are shown in figure 4. In this case, the results are normalised per 100000 people in the population as the size of the age groups varied widely. The results provide a strong indication that the burden of heat and cold remains much higher in age groups 75-84 and in particular over $85+$ years. Heat-related mortality in those over 65 years is expected to increase steeply in the second half of this century, while cold-related mortality will decrease at a 
Figure 1 (A) Region-specific and national-level relative risk $(95 \% \mathrm{Cl})$ of mortality due to hot weather. Daily mean temperature $93 \mathrm{rd}$ centiles:

North East $\left(16.6^{\circ} \mathrm{C}\right)$, North West $\left(17.3^{\circ}\right.$ C), Yorks \& Hum $\left(17.5^{\circ} \mathrm{C}\right)$, East Midlands $\left(17.8^{\circ} \mathrm{C}\right)$, West Midlands $\left(17.7^{\circ} \mathrm{C}\right)$, East England $\left(18.5^{\circ} \mathrm{C}\right)$, London $\left(19.6^{\circ} \mathrm{C}\right)$, South East $\left(18.3^{\circ} \mathrm{C}\right)$, South West $\left(17.6^{\circ} \mathrm{C}\right)$, Wales $\left(17.2^{\circ} \mathrm{C}\right)$. (B) Region-specific and national-level relative risk $(95 \% \mathrm{Cl})$ of mortality due to cold weather. Daily mean temperature 60th centiles: North East $\left(10.9^{\circ} \mathrm{C}\right)$, North West $\left(11.9^{\circ} \mathrm{C}\right)$, Yorks \& Hum $\left(11.5^{\circ} \mathrm{C}\right)$, East Midlands $\left(11.7^{\circ} \mathrm{C}\right)$, West Midlands $\left(11.6^{\circ} \mathrm{C}\right)$, East England $\left(12.2^{\circ} \mathrm{C}\right)$, London $\left(13.2^{\circ} \mathrm{C}\right)$, South East $\left(12.4^{\circ} \mathrm{C}\right)$, South West $\left(12.1^{\circ} \mathrm{C}\right)$, Wales $\left(11.9^{\circ} \mathrm{C}\right)$.

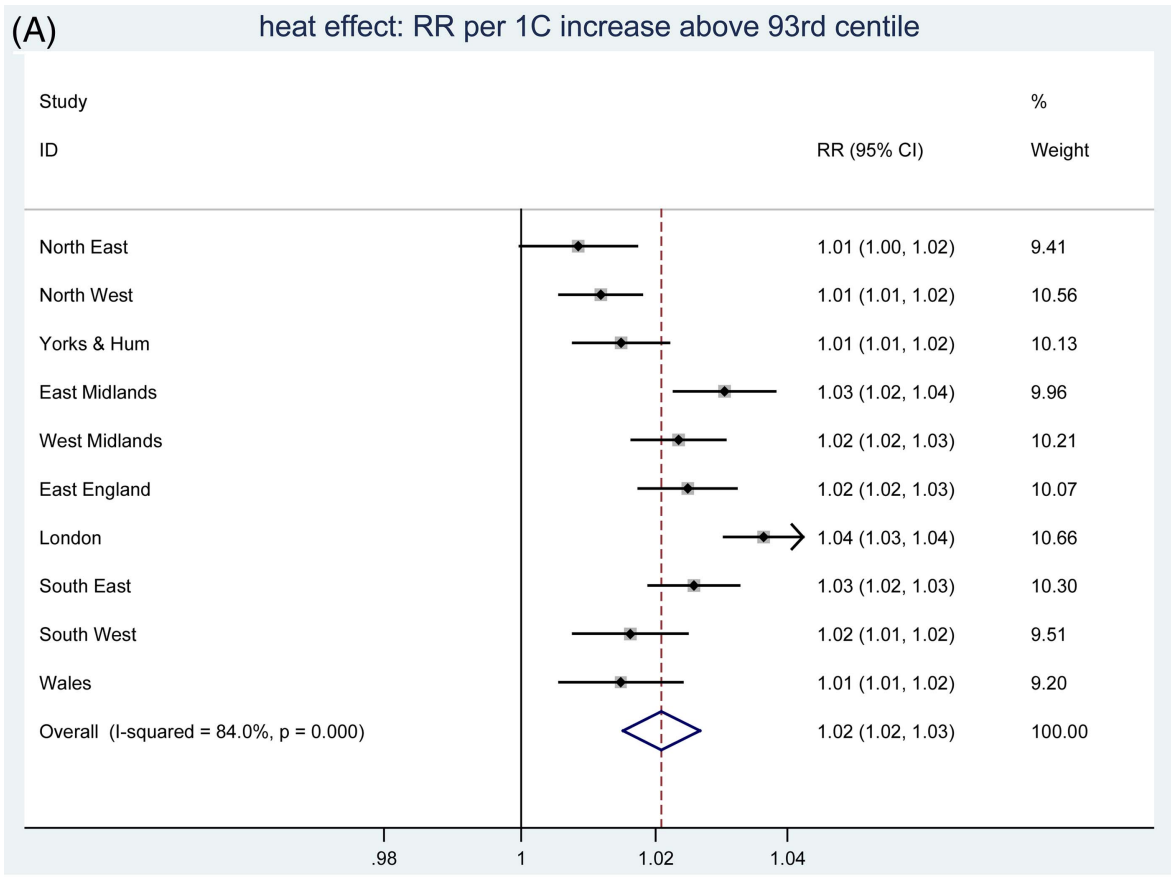

(B) cold effect: RR per $1 \mathrm{C}$ decrease below 60 th centile

Study
ID
North East

lower rate. For each age group, again the net number of temperature-related deaths per 100000 people declines in future decades due to the increased heat-related mortality rate being offset by a greater reduction in the cold-related mortality rate.

Current temperature-related mortality rates per 100000 people varied across UK regions (table 1). The regions in the south and the midlands had the highest rates of heat-related deaths, ranging between 3.5 and 6.3 deaths/year/100 000 people in the 2000s. Wales, North West, East England and the southern regions had the highest cold-related mortality rates (between 68.8 and 83.9 deaths/year/100 000 people). The regional variations to heat and cold will broadly persist in future decades.

\section{DISCUSSION \\ Summary of findings}

This study provides quantitative estimates of future temperaturerelated mortality burdens associated with climate change in a typical high-income country-in this case, the UK. It reveals that, in the absence of adaptation of the population, heat-related deaths would be expected to rise by around $257 \%$ by mid- 
Figure 2 UK hot days (top) and cold days (bottom) per decade for the 2020s, 2050s and 2080s expressed as a percentage of baseline hot and cold days, for nine regional climate model variants. Hot days are calculated as days above the 93rd centile baseline (2000s) temperature (252 hot days, mean temperature across models variants $=15.4^{\circ} \mathrm{C}$ for baseline). Similarly, cold days are days below the 60th centile baseline temperature ( 2160 cold days, mean temperature $=10.5^{\circ} \mathrm{C}$ for baseline). Middle line in boxes represents median value.
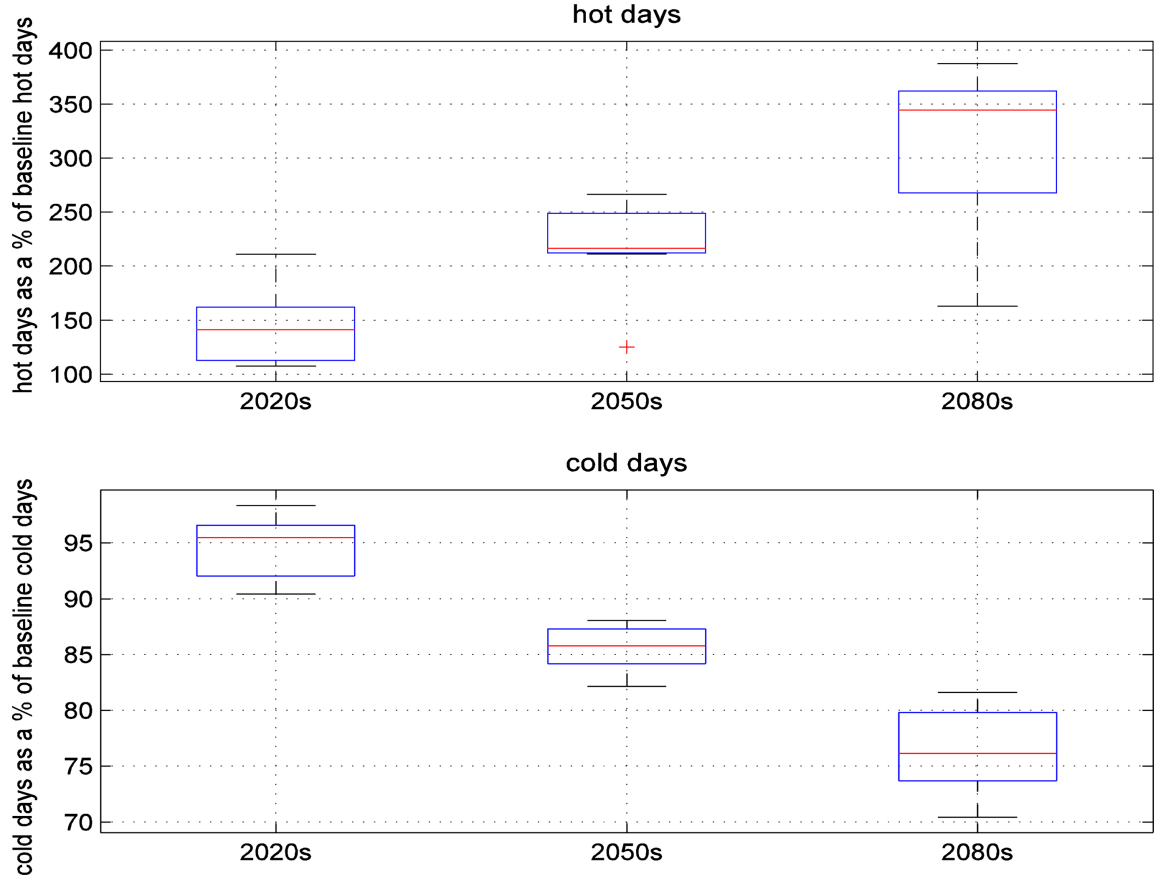

century compared with the beginning of the century, and cold-related deaths would decline by $2 \%$, with regional variations. These estimates take into account changes in population size and composition that are likely in the UK in this century. Such factors are shown to be key drivers in the increased number of future heat-related deaths.

\section{Comparison with previous work}

The estimated reduction in cold risk is similar to that in a previous study which modelled a 2-3\% reduction in wintertime deaths in England and Wales by 2050. ${ }^{18}$ Our estimate of future heat burdens agrees with a previous similar assessment which showed a $250 \%$ increase in annual heat-related deaths by the 2050s under a medium-high climate change scenario. ${ }^{19}$ However, the same work, which did not consider future demographic changes, observed a $25 \%$ reduction in cold-related deaths. Our work suggests that reductions in cold-related mortality are unlikely to be this large, partly due to future population ageing. Indeed, when demographic changes are not factored into our estimates, a $26 \%$ reduction in cold deaths was observed by the 2050s. Although other studies have estimated future heat burdens for London, ${ }^{20-22}$ there are few other UK-wide assessments.
Studies from other high-income settings have reported increases in heat-deaths of $77 \%$ in Portugal by the $2020 \mathrm{~s},{ }^{23}$ $70 \%$ in the US by the $2050 \mathrm{~s},{ }^{24}$ and $10 \%$ in Canada by the $2080 \mathrm{~s}^{25}$ A review paper summarises published estimates of future heat deaths, although comparisons between studies are difficult due to variations in the use of emission scenarios, climate models, future adaptation and demographic assumptions and modelling choices in epidemiological assessment. ${ }^{26}$

\section{Strengths and limitations}

Unlike most previous studies, we modelled greater variance in future temperatures as well as changes to mean levels. This was achieved by using a daily series of temperature projections and modelling separate impacts of heat-waves, but such an additional effect was only noteworthy in one region-London-where heatwaves made a substantial contribution to the overall heat burden. However, as the general heat effects were modelled using a lag of 0-1 days, any additional effect of the longer duration heat-wave term may also reflect general heat effects delayed by more than 1 day, rather than a true additional effect of sustained high temperatures. Hot and cold weather can also impact adversely on morbidity outcomes, but not as consistently as with mortality. ${ }^{27}$
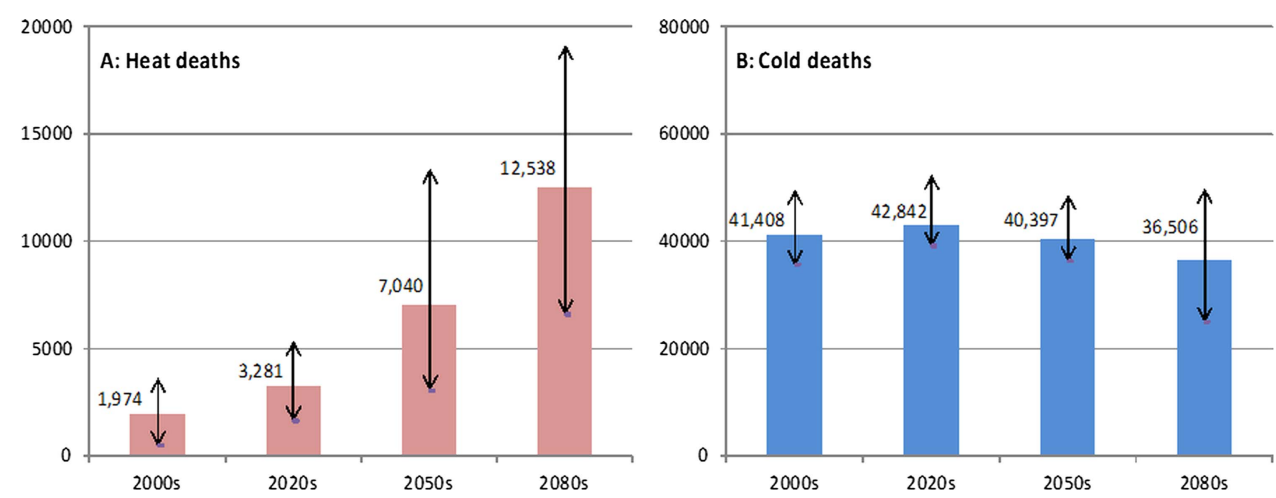

Figure 3 Heat-related (A) and cold-related (B) deaths in the UK per year for all ages based on an ensemble of nine climate model realisations. Mean estimates across the nine models are shown, and upper and lower limits of arrows represent the maximum and minimum of these. 


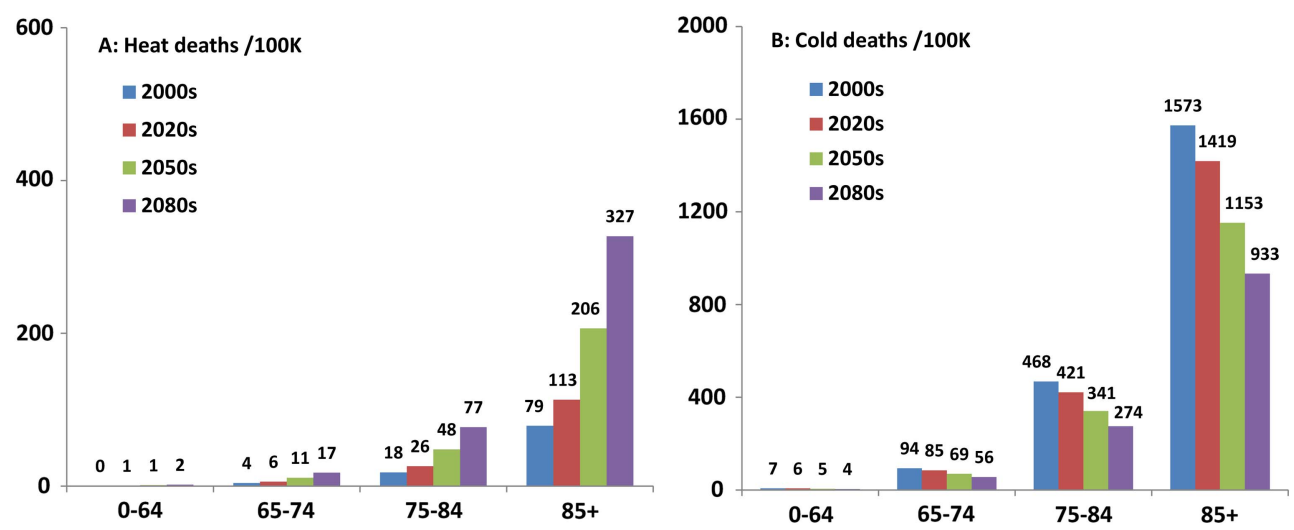

Figure 4 Mean estimates of heat-related and cold-related deaths in the UK per year per 100000 population, by age group.

Our study assessed the effects of climate change in the absence of adaptation. Although variations in temperature-risk between countries indicate that populations can adapt to their local climate conditions, the rate at which future temperatures are expected to rise and the increased variability will be unprecedented since agricultural times, making it unlikely that future societal adaptation to hot weather will be as achievable as in the past. Over time, there may be some degree of population adaptation in terms of physiology, behavioural changes and technological measures such as increased use of air-conditioning.
The adequacy with which the potential contribution of future acclimatisation and adaptation can be modelled into estimates of future impacts is unclear, and various approaches to model heat adaptation have been proposed. ${ }^{16} 28$ One study of US cities reported that an assumption of future adaptation, based on using analogue cities, reduced temperature-related deaths by $20-25 \%$ compared with no future adaptation. ${ }^{29}$ Previous trends in reduced cold-related risk due to improvements in healthcare, housing and other factors are also likely to continue. ${ }^{30} 31$

Table 1 Mean, minimum and maximum estimates of heat-related and cold-related deaths in UK regions/year/100000 population of all ages based on an ensemble of nine climate model realisations

\begin{tabular}{|c|c|c|c|c|c|c|c|c|c|c|c|c|}
\hline & \multicolumn{3}{|l|}{$2000 \mathrm{~s}$} & \multicolumn{3}{|l|}{$2020 \mathrm{~s}$} & \multicolumn{3}{|l|}{$2050 \mathrm{~s}$} & \multicolumn{3}{|l|}{$2080 \mathrm{~s}$} \\
\hline & Mean & Minimum & Maximum & Mean & Minimum & Maximum & Mean & Minimum & Maximum & Mean & Minimum & Maximum \\
\hline \multicolumn{13}{|l|}{ Heat deaths* } \\
\hline North East & 1.2 & 0.5 & 2.1 & 2.1 & 1.3 & 2.9 & 3.9 & 2.2 & 7.8 & 6.7 & 4.0 & 10.0 \\
\hline North West & 1.3 & 0.3 & 3.1 & 2.0 & 0.8 & 3.9 & 3.7 & 1.8 & 9.0 & 6.2 & 3.0 & 9.8 \\
\hline Yorks \& Hum & 1.4 & 0.5 & 2.8 & 2.3 & 1.1 & 3.8 & 4.4 & 2.0 & 9.8 & 7.6 & 3.8 & 12.1 \\
\hline East Midlands & 4.4 & 1.4 & 8.1 & 6.5 & 3.3 & 10.2 & 11.5 & 4.8 & 21.0 & 18.4 & 10.2 & 28.1 \\
\hline West Midlands & 4.2 & 1.1 & 8.3 & 6.1 & 3.0 & 10.0 & 11.1 & 5.0 & 22.0 & 17.2 & 8.8 & 25.9 \\
\hline East England & 3.9 & 1.1 & 7.4 & 5.6 & 2.9 & 8.8 & 9.9 & 3.9 & 17.6 & 15.5 & 8.1 & 23.8 \\
\hline London & 4.4 & 0.9 & 8.8 & 6.1 & 2.8 & 10.8 & 11.3 & 4.3 & 21.4 & 17.5 & 8.4 & 27.9 \\
\hline South East & 6.3 & 1.5 & 11.4 & 8.6 & 4.6 & 14.1 & 15.3 & 6.7 & 26.1 & 22.9 & 12.8 & 34.1 \\
\hline South West & 3.5 & 0.7 & 7.6 & 5.1 & 2.4 & 8.7 & 9.6 & 4.3 & 18.9 & 15.3 & 7.8 & 23.7 \\
\hline Wales & 2.4 & 0.7 & 5.7 & 3.5 & 1.6 & 5.8 & 6.5 & 3.1 & 14.3 & 10.6 & 5.3 & 16.2 \\
\hline Scotland & 0.7 & 0.2 & 1.5 & 1.3 & 0.3 & 2.2 & 2.4 & 1.3 & 5.2 & 4.4 & 2.6 & 7.2 \\
\hline Northern Ireland & 0.9 & 0.3 & 2.3 & 1.6 & 0.6 & 2.6 & 2.9 & 1.5 & 6.1 & 4.9 & 2.9 & 7.2 \\
\hline Total UK & 3.3 & 0.9 & 6.0 & 4.8 & 2.4 & 7.8 & 8.8 & 3.9 & 16.8 & 14.0 & 7.4 & 21.5 \\
\hline \multicolumn{13}{|l|}{ Cold deaths } \\
\hline North East & 60.4 & 52.9 & 73.7 & 53.9 & 47.7 & 68.1 & 44.1 & 38.6 & 54.9 & 35.0 & 23.8 & 49.1 \\
\hline North West & 76.5 & 67.9 & 91.6 & 69.6 & 63.1 & 85.8 & 57.7 & 51.7 & 69.8 & 47.4 & 33.5 & 64.2 \\
\hline Yorks \& Hum & 62.9 & 55.5 & 75.3 & 56.9 & 51.5 & 69.9 & 47.0 & 41.9 & 56.7 & 38.3 & 27.2 & 51.8 \\
\hline East Midlands & 67.3 & 57.0 & 80.8 & 60.7 & 55.6 & 74.2 & 48.9 & 44.2 & 59.1 & 39.3 & 27.1 & 53.9 \\
\hline West Midlands & 63.5 & 53.7 & 75.9 & 57.5 & 52.5 & 70.8 & 46.4 & 41.9 & 56.2 & 37.4 & 25.3 & 51.5 \\
\hline East England & 68.8 & 58.1 & 81.8 & 62.5 & 57.6 & 74.8 & 50.2 & 45.4 & 59.5 & 40.7 & 28.4 & 54.9 \\
\hline London & 77.3 & 65.9 & 89.6 & 71.0 & 65.8 & 83.1 & 58.4 & 53.2 & 67.5 & 48.8 & 35.7 & 63.0 \\
\hline South East & 71.2 & 59.6 & 84.3 & 64.6 & 58.8 & 77.0 & 51.6 & 45.7 & 60.9 & 41.6 & 28.5 & 56.3 \\
\hline South West & 70.5 & 60.0 & 85.4 & 63.5 & 56.6 & 79.2 & 49.7 & 44.3 & 60.6 & 38.6 & 24.4 & 56.0 \\
\hline Wales & 83.9 & 73.7 & 101.8 & 76.1 & 69.4 & 95.5 & 61.1 & 54.5 & 75.1 & 48.7 & 31.9 & 69.3 \\
\hline Scotland & 55.6 & 48.2 & 71.9 & 49.3 & 42.4 & 66.3 & 40.8 & 34.3 & 53.5 & 31.2 & 19.8 & 46.4 \\
\hline Northern Ireland & 46.7 & 40.3 & 59.4 & 41.5 & 35.5 & 55.0 & 34.1 & 29.2 & 43.6 & 26.5 & 16.6 & 39.1 \\
\hline Total UK & 68.7 & 59.4 & 82.5 & 62.3 & 57.1 & 76.4 & 50.6 & 45.7 & 61.0 & 40.9 & 28.2 & 56.0 \\
\hline
\end{tabular}

${ }^{*}$ The additional heat-wave effect in London is not included to aid regional comparisons. 
There is some uncertainty in future emission trajectories relating to the choice of climate emission scenarios. We used modelled temperature based on the A1B scenario, which is consistent with observations that current growth in emissions is tracking close to the mid-range of this scenario. ${ }^{32}$ Another important issue is that although our study presents the mean, minimum and maximum estimates of future deaths in order to represent the uncertainty associated with regional climate modelling, a full uncertainty analysis has not been undertaken.

\section{Implications for public health}

Our results indicate that health protection from hot weather will become increasingly necessary this century, and measures to reduce cold impacts will also remain important. Air-conditioning is likely to become more widely used in the UK, which will reduce heat vulnerability. However, the distribution of cooling systems may reflect socioeconomic inequalities unless they are heavily subsidised, and rising fuel costs may exacerbate this. The prevalence of air-conditioning among poor black households in four US cities was less than half that in white households, resulting in greater heat vulnerability. ${ }^{33}$ Also, increased reliance on active cooling systems in houses, hospitals and care homes could exacerbate energy consumption, climate change and the urban heat island effect. ${ }^{34}$ Furthermore, power outages during hot weather may heighten vulnerability among people habituated to air-conditioned environments. Deaths from accidental and non-accidental causes increased during a power outage in New York. ${ }^{35}$ Passive cooling options (eg, building orientation, shading, thermal insulation, choice of construction materials) implemented at the design stage of urban developments may be equally effective in reducing heat stress, and would be more environmentally sustainable.

As the contribution of population growth and ageing on future temperature-related health burdens will be large, the health protection of the elderly will be important. Reductions in heat and cold tolerance among the elderly can be caused by chronic health conditions and poor aerobic tolerance, rather than by increased age per se. Better general health and wellbeing of elderly individuals may help to alleviate some of the large burdens expected. However, the future pace of ageing may have hitherto unrecognised consequences for healthcare. ${ }^{36}$ Changes in household size and living patterns may also be important modifiers of future risk among the elderly-many who died during the Paris 2003 heat-wave were living on their own and had limited social contact. ${ }^{37}$ Health protection measures to combat heat risk in Philadelphia, USA, include a community-based buddy system whereby vulnerable individuals are checked on by neighbours during hot weather. ${ }^{38}$

In England, the Department of Health now has heat-wave and cold weather protection plans (https://www.gov.uk/ government/uploads/system/uploads/attachment_data/file/201039/ Heatwave-Main_Plan-2013.pdf and https://www.gov.uk/ government/uploads/system/uploads/attachment data/file/252838/ Cold_Weather_Plan_2013_final.pdf). These aim to minimise the dangers of adverse weather conditions, including advice for the public and organisations on the protection of vulnerable people. Similar plans are in operation in other parts of the world, ${ }^{39} 40$ although there is still little quantitative evidence on their efficacy.

\section{CONCLUSIONS}

The UK experiences a substantial annual mortality burden associated with current weather patterns, with the fraction of deaths attributable to cold exposure currently being much larger than that due to heat. The elderly are most at risk. Certain UK regions also appear more vulnerable, which may reflect differences in demographic, health and built-environment characteristics. Future changes in climate are likely to lead not only to an increase in heat-related deaths in the UK, but also to a proportionally smaller decrease in cold-related deaths. The changing size and age structure of the population will contribute greatly to future burdens. Further work should focus on the modelling of spontaneous and planned adaptation to rising temperatures.

\section{What is already known on this subject}

- Many countries worldwide experience appreciable burdens of heat-related and cold-related deaths associated with current weather patterns.

- Climate change will quite likely alter such risks, but details as to how remain unclear.

\section{What this study adds}

- Without adaptation, heat-related deaths would be expected to rise by around $257 \%$ by the 2050 s from a current annual baseline of around 2000 deaths, and cold-related mortality would decline by $2 \%$ from a baseline of around 41000 deaths.

- The increase in future temperature-related deaths is partly driven by expected population growth and ageing.

- The health protection of the elderly will be vital in determining future temperature-related health burdens.

Acknowledgements The work presented in this paper is based on the Health Protection Agency report 'Health Effects of Climate Change in the UK 2012current evidence, recommendation and research gaps' sponsored by the Department of Health. The following sources of data and information are acknowledged: British Atmospheric Data Centre (BADC), the Met Office Hadley Centre, the UK Climate Impacts Programme (UKCIP), the Office for National Statistics (ONS).

Contributors SH conducted the epidemiological analysis. SV, CH and BE conducted the risk assessment. All authors contributed to the writing of the manuscript.

Funding This research has been funded by the Department of Health.

Competing interests None.

Provenance and peer review Not commissioned; externally peer reviewed.

\section{REFERENCES}

1 McMichael AJ, Wilkinson P, Kovats RS, et al. International study of temperature, heat and urban mortality: the 'ISOTHURM' project. Int J Epidemiol 2008;37:1121-31.

2 Basu R, Samet JM. Relation between elevated ambient temperature and mortality: a review of the epidemiologic evidence. Epidemiol Rev 2002;24:190-202.

3 Fearn V, Carter J. Excess winter mortality in England and Wales, 2008/09 (provisional) and 2007/08 (final). Health Stat Q 2009;44:69-79.

4 Johnson H, Kovats RS, McGregor G, et al. The impact of the 2003 heat wave on daily mortality in England and Wales and the use of rapid weekly mortality estimates. Euro Surveill 2005;10:168-71.

5 Jones GS, Stott PA, Christidis N. Human contribution to rapidly increasing frequency of very warm Northern Hemisphere summers. J Geophys Res 2008;113:D02109, doi:10.1029/2007JD008914

6 Kodra E, Steinhaeuser K, Ganguly AR. Persisting cold extremes under 21st-century warming scenarios. Geophys Res Lett 2011;38:L08705, doi:10.1029/ $2011 \mathrm{GL} 047103$

7 Vardoulakis S, Heaviside C. Health effects of climate change in the UK 2012-current evidence, recommendations and research gaps. Health Prot Agency 2012:236. 
8 Armstrong BG, Chalabi Z, Fenn B, et al. Association of mortality with high temperatures in a temperate climate: England and Wales. J Epidemiol Community Health 2010;65:340-5.

9 Bhaskaran K, Hajat $S$, Haines A, et al. Short term effects of temperature on risk of myocardial infarction in England and Wales: time series regression analysis of the Myocardial Ischaemia National Audit Project (MINAP) registry. BMJ 2010;341: c3823.

10 Meehl GA, Tebaldi C. More intense, more frequent, and longer lasting heat waves in the 21st century. Science 2004;305:994-7.

11 Fischer EM, Schar C. Consistent geographical patterns of changes in high-impact European heatwaves. Nat Geosci 2010;3:398-403.

12 Anderson GB, Bell ML. Heat waves in the United States: mortality risk during heat waves and effect modification by heat wave characteristics in 43 US communities. Environ Health Perspect 2011:119:210-18.

13 Barnett AG, Hajat S, Gasparrini A, et al. Cold and heat waves in the United States. Environ Res 2012:112:218-24.

14 Jenkins GJ, Murphy JM, Sexton DMH, et al. UK climate projections: briefing report. Exeter, UK: Met Office Hadley Centre, 2009.

15 ONS. National population projections, 2010-based projections. Office for National Statistics, 2011. http://www.ons.gov.uk/ons/rel/npp/national-population-projections/ 2010-based-projections/index.html

16 Kinney PL, O'Neill MS, Bell ML, et al. Approaches for estimating effects of climate-change on heat-related deaths: challenges and opportunities. Environ Sci Policy 2008:87-96.

17 Gosling SN, Lowe JA, McGregor GR, et al. Associations between elevated atmospheric temperature and human mortality: a critical review of the literature. Climatic Change 2009;92:299-341

18 Langford $\mathrm{IH}$, Bentham $\mathrm{G}$. The potential effects of climate change on winter mortality in England and Wales. Int J Biometeorol 1995;38:141-7.

19 Donaldson G, Kovats RS, Keatinge WR, et al. Heat- and cold-related mortality and morbidity and climate change. London: Department of Health, 2002.

20 Martens WJ. Climate change, thermal stress and mortality changes. Soc Sci Med 1998:46:331-44.

21 Kalkstein LS. A heat/mortality analysis for London: some climate change implications. London: World cities leadership climate change summit, 2005.

22 Gosling SN, McGregor GR, Lowe JA. Climate change and heat-related mortality in six cities Part 2: climate model evaluation and projected impacts from changes in the mean and variability of temperature with climate change. Int J Biometeorol 2009;53:31-51.

23 Casimiro E, Calheiros J, Santos FD, et al. National assessment of human health effects of climate change in Portugal: approach and key findings. Environ Health Perspect 2006;114:1950-6.
24 Knowlton K, Lynn B, Goldberg RA, et al. Projecting heat-related mortality impacts under a changing climate in the New York City region. Am J Public Health 2007:97:2028-34.

25 Doyon B, Belanger D, Gosselin P. The potential impact of climate change on annual and seasonal mortality for three cities in Quebec, Canada. Int J Health Geogr 2008;7:23.

26 Huang $C$, Barnett $A G$, Wang $X$, et al. Projecting future heat-related mortality under climate change scenarios: a systematic review. Environ Health Perspect 2011;119:1681-90.

27 Hajat $\mathrm{S}, \mathrm{O}^{\prime}$ Connor $\mathrm{M}$, Kosatsky $\mathrm{T}$. Health effects of hot weather: from awareness of risk factors to effective health protection. Lancet 2010;375:856-63.

28 Christidis N, Donaldson G, Stott PA. Causes for the recent changes in cold- and heat-related mortality in England and Wales. Climatic Change 2010;102:539-53.

29 Kalkstein LS, Greene JS. An evaluation of climate/mortality relationships in large U.S. cities and the possible impacts of a climate change. Environ Health Perspect 1997:105:84-93.

30 Donaldson GC, Keatinge WR. Mortality related to cold weather in elderly people in southeast England, 1979-94. BMJ 1997;315:1055-6.

31 Carson C, Hajat S, Armstrong B, et al. Declining vulnerability to temperature-related mortality in London over the 20th century. Am J Epidemiol 2006;164:77-84.

32 Peters GP, Andrew RM, Boden T, et al. The challenge to keep global warming below 2C. Nat Climate Change 2013;3:4-6.

33 O'Neill MS, Zanobetti A, Schwartz J. Disparities by race in heat-related mortality in four US cities: the role of air conditioning prevalence. J Urban Health 2005;82:191-7.

34 Oke TR. City size and the urban heat island. Atmos Environ 1973;7:769-79.

35 Anderson GB, Bell ML. Lights out: impact of the August 2003 power outage on mortality in New York, NY. Epidemiology 2012;23:189-93.

36 Vaupel JW. Biodemography of human ageing. Nature 2010;464:536-42.

37 Vandentorren S, Bretin P, Zeghnoun A, et al. August 2003 heat wave in France: risk factors for death of elderly people living at home. Eur J Public Health 2006;16:583-91.

38 Sheridan SC. A survey of public perception and response to heat warnings across four North American cities: an evaluation of municipal effectiveness. Int $J$ Biometeorol 2007:52:3-15.

39 Lowe D, Ebi KL, Forsberg B. Heatwave early warning systems and adaptation advice to reduce human health consequences of heatwaves. Int J Environ Res Public Health 2011:8:4623-48

40 Dabrera G, Murray V, Carmichael C. Cold Weather Threats to Health: How Does Europe Prepare? Public Health 2013;doi:pii:S0033-3506(13)00127-3 